Available online at http://jddtonline.info

RESEARCH ARTICLE

\title{
IN VITRO ANTIINFLAMMATORY ACTIVITY OF JUGLANS REGIA BARK
}

\author{
Verma Ankit Kumar, Agarwal Kshitij*, Saini Prem \\ Dev Bhoomi Institute of Pharmacy and Research, Dehradun, India \\ *Corresponding Author's Email: tanupharma@gmail.com
}

\begin{abstract}
To evaluate the anti-inflammatory property of the different extract of bark of Juglans regia, family Juglandaceae is a deciduous tree. Its fruits are consumed as food, which are rich in unsaturated fatty acids. Walnut leaf has been widely used in traditional medicine for the treatment of skin inflammations and ulcers and for its antidiarrheic, antihelmintic, antiseptic and astringent properties. The present study aimed at the evaluation of anti-inflammatory property of the aqueous, chloroform and alcoholic extracts of the bark by in vitro methods. In vitro method was estimated by human red blood cell membrane stabilization (HRBC) method. Results showed significant anti-inflammatory property of the different extracts tested. The aqueous extract at a concentration of $200 \mathrm{mg} / \mathrm{ml}$. showed potent activity on comparing with the standard drug diclofenac sodium.
\end{abstract}

Key words: Juglans regia, HRBC, Inflammation and dicloenac.

\section{INTRODUCTION}

Inflammation is a reaction of living tissues towards injury and it comprises systemic and local responses ${ }^{1}$. In spite of our dependence on modern medicine and the tremendous advances in synthetic drugs, a large number of the world populations (80\% of people) cannot afford the products of the pharmaceutical industry and have to rely upon the use of traditional medicines, which are mainly derived from plant material. The fact is well recognized by the WHO which has recently compiled an inventory of medicinal plants listing over 20000 species. There are several important medicinal plants with wide range of pharmacological, biological activities and interesting phyto chemical constituents. The main action of anti-inflammatory agents is the inhibition of Cyclooxegenase enzymes which are responsible for the conversion of Arachidonic acid to prostaglandins. Since human red blood cell (HRBC) membranes are similar to these lysosomal membrane components, the prevention of hypotonicity induced HRBC membrane lysis was taken as a measure in estimating the anti-inflammatory property of various extracts of Juglans regia. Thus, Human red blood cell membrane stabilization (HRBC method) ${ }^{2,3}$ has been used as a method in estimating the anti-inflammatory property. Barks of Juglans regia consist of several constituents like Gallic acid, Quercetin, Coumarin,etc but the most active constituent isan aromatic phytochemical Juglone $\left(\mathrm{C}_{10} \mathrm{H}_{6} \mathrm{O}_{3}\right.$; $1,4-$ napthaquinone, 5 hydroxy $-8 \mathrm{Cl}$ ) and juglanin $\mathrm{A}, \mathrm{B}, \mathrm{C}$ and the volatile constituents are given as Alpha-thujene, sabinene, p-cymene, 1,8-cineole, alpha-cardinol, Benzyl alcohol, alpha-Bisabalol, Linalol,Isopuegol, Carvacrol, Myretenal, Estrsgol, Pinocarveol, Globulol, Verbenol. In certain parts of India the bark of this plant was traditionally used in the treatment of inflammation. The present study aimed to authenticate that traditional information by in vitro antiinflammatory screening.

(C) 2011, JDDT. All Rights Reserved

ISSN: 2250-1177

\section{MATERIALS AND METHODS}

\section{Preparation of extracts}

Fresh bark of Juglans regia were collected from FRI, Dehradun and were authenticated by botanist. The bark were dried in shade and powdered to a coarse form. It was then successively extracted with methanol, ethanol, water and hydroalcohol using continuous cold maceration process. The extracts were concentrated under reduced pressure and preserved at low temperature.

\section{Chemicals and instruments}

All chemicals used in the estimation were of analytical grade. Reference standard diclofenac sodium was obtained as gift sample from Arbro pharmaceutical, New Delhi. Shimadzu 1701 UV Visible spectrophotometer was used for the in vitro study.

\section{In vitro Anti-inflammatory activity}

The blood was collected from healthy human volunteer who had not taken any NSAIDS for 2 weeks prior to the experiment and mixed with equal volume of Alsever solution( $2 \%$ dextrose, $0.8 \%$ sodium citrate, $0.5 \%$ citric acid and $0.42 \% \mathrm{NaCl}$ ) and centrifuged at 3,000 rpm. The packed cells were washed with isosaline and a $10 \%$ suspension was made. Various concentrations of extracts were prepared (100 and $200 \mu \mathrm{g} / \mathrm{ml}$ ) using distilled water and to each concentration $1 \mathrm{ml}$ of phosphate buffer, $2 \mathrm{ml}$ hyposaline and $0.5 \mathrm{ml}$ of HRBC suspension were added. It was incubated at $370 \mathrm{C}$ for $30 \mathrm{~min}$ and centrifuged at 3,000 rpm for $20 \mathrm{~min}$. and the hemoglobin content of the supernatant solution was estimated on UV spectrophotometer at $560 \mathrm{~nm}$. Diclofenac $(100$ and $200 \mathrm{~g} / \mathrm{ml}$ ) was used as reference standard and a control was prepared by omitting the extracts. ${ }^{4,5}$ 


\section{RESULT}

\section{In vitro anti-inflammatory activity}

Juglans regia extracts at different concentrations (100, 200 $\mathrm{mg} / \mathrm{mL}$ ) showed significant stabilization towards HRBC membranes. The percentage protection of aqueous extract at concentration $200 \mathrm{mg} / \mathrm{mL}$ was higher than that of other concentrations. However the percentage protection was found to be lesser then the reference concentration. The results were tabulated in Table 1.

Table 1: \% inhibition of different extracts of the Juglans regia

\begin{tabular}{|l|l|l|l|l|}
\hline S. No. & Type of extract & Concentration $(\boldsymbol{\mu g} / \mathbf{m l})$ & Absorbance & \% Inhibition of denaturation \\
\hline 1 & Control & & $0.019 \pm 1.20$ & \\
\hline 2 & Water & 200 & $0.773 \pm 1.20$ & $32.02 \pm 0.21$ \\
\hline 3 & Water & 100 & $0.0260 \pm 0.023$ & $40.76 \pm 1.23$ \\
\hline 4 & Chloroform & 200 & $0.0331 \pm 1.20$ & $29.30 \pm 0.022$ \\
\hline 5 & Chloroform & 100 & $0.0409 \pm 0.24$ & $23.71 \pm 1.015$ \\
\hline 6 & Methanol & 200 & $0.0292 \pm 0.323$ & $36.30 \pm 0.019$ \\
\hline 7 & Methanol & 100 & $0.0405 \pm 0.021$ & $23.70 \pm 1.03$ \\
\hline 8 & Diclofenac & 100 & $0.0374 \pm 0.121$ & $79.25 \pm 1.025$ \\
\hline 9 & Diclofenac & 200 & $0.0207 \pm 1.25$ & $88.43 \pm 0.029$ \\
\hline
\end{tabular}

\section{DISCUSSION}

Inflammation is a common phenomenon and it is a reaction of living tissues towards injury. Steroidal anti-inflammatory agents will lyse and possibly induce the redistribution of lymphocytes, which cause rapid and transient decrease in peripheral blood lymphocyte counts to affect longer term response. Phytochemical evaluation of the various extracts of Juglans regia reveals the presence of flavonoids, glycosides, saponins, steroids, tannins and polyphenols. Here antiinflammatory activity was performed based on the folk lore information using two methods. HRBC method was selected for the in vitro evaluation of anti-nflammatory property because the erythrocyte membrane is analogous to the lysosomal membrane ${ }^{6]}$ and its stabilization implies that the extract may as well stabilize lysosomal membranes. Stabilization of lysosomal membrane is important in limiting the inflammatory response by preventing the release of lysosomal constituents of activated neutrophil, such as bactericidal enzymes and proteases, which cause further tissue inflammation and damage upon extra cellular release. The result indicted that the bark extract of Juglans regia at various concentrations has significant anti-inflammatory property. The present result indicates the efficacy of Juglans regia as an effective therapeutic agent in the treatment of acute inflammations. The result of present study authentifies the folk lore information on the anti-inflammatory property of the bark extract of Juglans regia . Further and detailed studies are in process for the isolation of active constituent responsible for this property and to identification of the possible mechanism of its anti inflammatory property. ${ }^{7}$

\section{ACKNOWLEDGEMENT}

The authors are thankful to the chairman, and faculties of Dev Bhoomi Institute of Pharmacy and Research, Dehradun for rendering the necessary requirements in this work.

\section{REFERENCES}

1. Ejebe DE, Siminialayi IM, Emudainowho JOT, Ofesi U, Morka L, Analgesic and anti-inflammatory activities of the ethanol extract of the bark of Helianthus Annus in Wistar rats, Asian Pac J Trop Med, 2010, 3(5), 341-347.

2. Azeem AK, Dilip C, Prasanth SS, Junise V, Hanan Shahima, Antiinflammatory activity of the glandular extracts of Thunnus alalunga, Asia Pac J For Med, 2010, 3(10), 412-420.

3. Gandhidasan R, Thamaraichelvan A, Baburaj, Antiinflamattory action of Lanea coromondelica by HRBC membarane stabilization, Fitotherapia, 1991, 62, 82-83.
4. Shenoy S, Shwetha K, Prabhu K, Maradi R, Bairy KL, Shanbhag T, Evaluation of antiinflammatory activity of Tephrosia purpurea in rats, Asian Pac J Trop Med, 2010, 3(3), 193-195.

5. Georgewill OA, Georgewill UO, Nwankwoala RNP, Antiinflammatory effects of Morninga oleifera lam extract in rats, Asian Pac J Trop Med, 2010, 3(2), 133-135.

6. Winter CA, Risley EA, Nuss GW, Carrageenan induced oedema in hind paws of the rats as an assay for anti-inflammatory drugs, Proc Soc Exp Bio Med, 2002, 111, 544-557.

7. Georgewill OA, Georgewill UO, Evaluation of the antiinflammatory activity of extract of Vernonia Amygdalina, Asian Pac J Trop Med, 2010, 3(2), 150-151. 